\section{A LINGUAGEM COMO INSTRUMENTO DE INCLUSÃO SOCIAL: UMA EXPERIÊNCIA DE ENSINO DO HIP HOP PARA JOVENS E ADULTOS COM DEFICIÊNCIA INTELECTUAL E AUTISMO}

\author{
LANGUAGE AS AN INSTRUMENT FOR SOCIAL INCLUSION: A HIP- \\ HOP TEACHING EXPERIENCE FOR YOUTH AND ADULTS WITH \\ INTELLECTUAL DISABILITY AND AUTISM
}

\author{
EL LENGUAJE COMO UN INSTRUMENTO DE INCLUSIÓN SOCIAL: \\ UNA EXPERIENCIA DE ENSEÑANZA DEL HIP-HOP PARA JÓVENES Y \\ ADULTOS CON DEFICIENCIA INTELECTUAL Y AUTISMO
}

\author{
Ingrid Rosa Carvalho*, Joyce Klein*, Daiane Matheus Pessoa*, \\ José Francisco Chicon*, Maria das Graças Carvalho Silva de Sá*
}

\begin{abstract}
Palavras chave: Educação Física. Dança.

Pessoas com deficiência. Inequidade social.

Resumo: Objetiva compreender e analisar as diversas manifestações de linguagem produzidas ao longo de uma experiência de ensino do hip hop e seus desdobramentos para o reconhecimento juvenil de jovens e adultos com deficiência intelectual e autismo. Também problematiza as possíveis contribuições dessa experiência para os processos de inclusão social dos envolvidos. Adota a pesquisa qualitativa fundamentada na pesquisa-ação existencial. Foram considerados a partir da análise categorial de conteúdos. A pesquisa evidenciou que o processo de mediação da cultura hip hop fomentou a compreensão sobre as diversas formas e possibilidades de linguagem produzidas com o grupo de modo crítico e criativo, sem desconsiderar as potencialidades, o protagonismo e o reconhecimento da condição juvenil ou adulta dos participantes. Favorece, assim, os processos de inclusão social, ao proporcionar momentos de reconhecimento social e de produção de linguagem, contribuindo com a redução do hiato na interlocução com os demais sujeitos sociais.
\end{abstract}

Keywords:

Physical

Education

Dancing.

Disabled persons

Social inequity

Palabras clave: Educación Física. Baile.

Personas con discapacidad Inequidad social.

Abstract: This article aims at understanding and analyzing distinct instances of language produced during a hip-hop teaching experience and its consequences for social recognition of the condition of youth and adults with disabilities. It also discusses the possible contributions of that experience to processes of social inclusion of those involved. Methods: qualitative research based on existential research-action, based on categorical content analysis. Results: the mediation process of hip-hop culture fostered understanding of the various forms and possibilities of language produced in or with the group in a critical and creative way, without disregarding the potentialities, the central role and the recognition of the project participants' condition as youth or adults. Conclusions: the experience favored processes of social inclusion by providing moments of social recognition and language production, thus contributing to reduce the gap in their interlocution with other social subjects.

Resumen: Busca comprender y analizar las diversas manifestaciones de lenguaje producidas a lo largo de una experiencia de enseñanza del hip-hop y sus desdoblamientos para el reconocimiento juvenil de jóvenes y adultos con deficiencia intelectual y autismo. También problematiza las posibles contribuciones de esa experiencia para los procesos de inclusión social de los involucrados. Adopta la investigación cualitativa fundamentada en la investigación-acción existencial. Fueron considerados a partir del análisis de categoría de contenidos. La investigación mostró que el proceso de mediación de la cultura hip-hop fomentó la comprensión sobre las diversas formas y posibilidades de lenguaje producidas con el grupo de modo crítico y creativo, sin desconsiderar las potencialidades, o protagonismo y el reconocimiento de la condición juvenil o adulta de los participantes, favoreciendo los procesos de inclusión social, al proporcionar momentos de reconocimiento social y de producción de lenguaje, contribuyendo con la reducción de la brecha en la interlocución con los demás sujetos sociales.
*Universidade Federal do Espírito Santo. Vitória, ES, Brasil. E-mail: ingridrosa.c@outlook.com; joyceklein10@gmail.com; daimpessoa@gmail.com; chiconjf@yahoo.com.br; mgracasilvasa@gmail.com

Recebido em: 28-03-2019 Aprovado em: $14-04-2020$ Publicado em: 07-05-2020 


\section{INTRODUÇÃO}

Historicamente, a inclusão de pessoas com deficiência no Brasil vem se construindo por meio de conflitos e tensões na busca por se consolidar uma atitude social que reconheça e respeite a diferença e a compreenda como um reordenamento legal que garanta condições de equidade a todos/as. Embora já tenham sido conquistados avanços legais, sabemos que ainda não se alcançou patamar satisfatório no sentido de se dirimir os efeitos das desigualdades em que boa parte dessa população se encontra.

Entretanto, na contramão desse pressuposto ainda se faz presente, no imaginário social, um olhar preconceituoso, discriminatório e desrespeitoso em relação aos direitos sociais desses indivíduos. Recorrentemente identificamos ações discriminatórias e infantilizadas direcionadas a esse público, mesmo quando essas pessoas já atingiram a fase juvenil e/ou adulta, uma sociedade descrente das reais potencialidades e possibilidades deles. Esse cenário gera barreiras para que esses indivíduos possam ter acesso às criações culturais, ocasionando dificuldades para se tornarem protagonistas de suas vidas cotidianas (SAWAIA, 2001).

Um dos grandes fatores desencadeadores está na forma peculiar como esses indivíduos se utilizam da linguagem ${ }^{1}$ para interagir socialmente, visto que muitos não se expressam por meio da oralidade socialmente instituída.

Os estudos de Bakhtin (1999) e Vygotsky (2007) nos apontam que, por meio da linguagem, os indivíduos têm acesso à cultura, elemento determinante para o desenvolvimento humano. Para tanto, faz-se necessária uma compreensão multidimensional sobre as diversas possibilidades de instituição social da linguagem, sendo ela a principal ferramenta mediadora das interações dos indivíduos com o mundo e com os outros, que o torna seres socialmente inscritos.

Considerando esses argumentos, é importante destacar que trabalhamos em um Laboratório Universitário que vem se estabelecendo como um agente potencializador na/para a formação inicial e continuada de professores de educação física, na perspectiva inclusiva.

Nesse caminho, atendemos jovens e adultos com deficiência intelectual ${ }^{2} \mathrm{e}$ autismo ${ }^{3}$, matriculados no projeto permanente de extensão "Prática pedagógica de educação física adaptada para pessoas com deficiência" que promove ações pedagógicas com caráter inclusivo, com foco na formação humana, auxiliando-os na apropriação e ressignificação de conhecimentos que Ihes possibilitem a autonomia e a independência necessária para que possam se relacionar com o meio sociocultural.

\footnotetext{
1 Adotamos o conceito de linguagem como um complexo sistema de códigos que designa objetos, ações ou relações, de construção histórico/cultural polifônica que se expressa de diversas formas e possibilidades, como um instrumento responsável pelas interações sociais entre os indivíduos (BAKHTIN, 1999; VYGOTSKY, 2007).

2 Funcionamento Intelectual abaixo da média, manifestado antes dos dezoito anos, associados a duas ou mais limitações relacionadas a habilidades adaptativas, tais como comunicação, cuidado pessoal, habilidades acadêmicas, entre outras áreas (SALTON; ALGNOL; TURCATTI, 2017, p. 26).

3 Adotamos o conceito de autismo de acordo com o Manual Diagnóstico e Estatistico de Transtornos Mentais (DSM-V), publicado no ano de 2013, sendo considerado "[...] uma condição do desenvolvimento neurológico, caracterizado por uma alteração da comunicação social e pela presença de comportamentos repetitivos e estereotipados" (BARROS; TRUGILHO, 2019, p. 76).
} 
Assim, a pesquisa em tela emergiu da demanda advinda de intervenções com esse público em que constatamos que, para além da necessidade de reconhecimento social sobre a sua condição juvenil e/ou adulta, havia um desafio maior a enfrentarmos, no sentido da superação das dificuldades existentes na comunicação entre os alunos e os professores do projeto, em virtude da dificuldade em lidar com a diversidade de expressão/linguagem apresentada pelos alunos.

Em frente a essa situação, identificamos a necessidade de melhor entender as diversas formas de linguagem utilizadas por esse público para se expressar socialmente. Esse olhar multidimensional se fez necessário, para melhor compreendermos como as práticas corporais experimentadas por eles nas aulas, estavam sendo internalizadas e ressignificadas.

Na busca por constituir um corpus teórico-conceitual para melhor compreender esse cenário, retomamos os registros sobre as intervenções anteriores envolvendo a dança numa perspectiva criativa, percebendo-a como uma potente ferramenta de linguagem, com base nos estudos histórico-culturais (BAKHTIN, 1999; VYGOTSKY, 2007). Assim, compreendemos que a linguagem expõe uma extensa variedade de formas de expressão, o que se reflete nas relações sociais por meio dos símbolos e significados atribuídos a bens culturais e materiais nas diferentes internalizações e produções humanas.

Com base nessas considerações, este estudo objetivou compreender e analisar as diversas manifestações de linguagem produzidas ao longo de uma experiência de ensino do hip hop e seus desdobramentos para o reconhecimento de jovens e adultos com deficiência intelectual e autismo. Interessa-nos, ainda, problematizar sobre as possíveis contribuições que a mediação da cultura hip hop fomentou nos processos de inclusão social dos envolvidos.

\section{DELINEAMENTO TEÓRICO-METODOLÓGICO}

Esta pesquisa se constitui em um estudo qualitativo fundamentado nos princípios teórico-metodológicos da pesquisa-ação existencial, na perspectiva de René Barbier (2002). Esse tipo de pesquisa mobiliza a valorização da realidade e de aspectos da afetividade dos sujeitos (amor, sofrimento, felicidade, vida social alternativa etc.), a partir do movimento constante de reflexão-ação sobre as realidades vividas com foco na transformação dos sujeitos e do mundo (BARBIER, 2002).

Assim, para atingir os objetivos propostos, este estudo foi realizado no período de março a dezembro de 2017, em uma aula semanal, todas as quintas-feiras, das 14 às 16 horas, totalizando 32 aulas ministradas. Contou com a participação de 20 jovens e adultos com deficiência intelectual e autismo, oriundos das comunidades da Grande Vitória-ES, com idades entre 16 e 60 anos, matriculados do projeto de extensão: "Prática pedagógica de educação física adaptada para pessoas com deficiência".

Ademais, colaboraram com o estudo, em planejamento, avaliação e registros, de maneira coletiva, ${ }^{4}$ uma professora/coordenadora, uma professora de 
Educação física, uma mestranda, cinco bolsistas de extensão, cinco discentes e dois voluntários.

Os dados foram coletados por registros audiovisuais (filmagens das aulas) e diário de campo. Foram organizados e categorizados pela análise de conteúdos (BARDIN, 1977). Ao identificar as categorias, passamos à etapa de apresentação, análise e discussão dos dados.

No âmbito da dinâmica didático-metodológica do projeto em tela, as aulas ocorriam semanalmente, com duração de duas horas. Os planejamentos eram produzidos de forma coletiva ao longo das reuniões de avaliação que aconteciam após cada intervenção, mediadas pelos bolsistas e estagiários, sob orientação e assessoria da professora gestora e da coordenadora do projeto.

Nesse transcurso, elegemos o hip hop como conteúdo de ensino a ser internalizado e ressignificado pelos alunos. Para tanto, foi necessário nos apoiarmos em uma perspectiva multidimensional sobre a linguagem, para melhor compreender esse universo, principalmente pelas diferentes manifestações presentes nessa cultura (BAKHTIN, 1999).

\section{MANIFESTAÇÕES DA LINGUAGEM NO HIP HOP: INTERNALIZAÇÕES E PRODUÇÕES}

O hip hop, cultura urbana e parte do desenvolvimento histórico da humanidade, surgiu na periferia de Nova lorque, entre as comunidades afro-americanas e latinoamericanas na década de 1970, quando o contexto de violência e criminalidade as fizeram encontrar na música, poesia, dança e pintura uma forma de manifestação e contestação de sua realidade. No Brasil, essa manifestação cultural chega na década de 1980, em princípio "[...] com o caráter de luta, reivindicação e consolidação da cidadania para as classes empobrecidas principalmente" (OLIVEIRA; SILVA, 2004, p. 68).

Esse fenômeno cultural permite uma enorme variedade de abordagens por ser uma manifestação rica e complexa que compreende, além da mobilização social, diversas formas de linguagem constituídas por quatro elementos:

[...] o break (a dança de passos robóticos, quebrados e, quando realizada em equipe, sincronizados), o grafite (a pintura, normalmente feita com spray, aplicada nos muros da cidade), o DJ (o disc-jóquei) e o rapper (ou MC, mestre de cerimônias, aquele que canta ou declama as letras sobre as bases eletrônicas criadas e executadas ao vivo pelo DJ). A junção dos dois últimos elementos resulta na parte musical do hip hop: o rap (abreviação de rythym and poetry, ritmo e poesia, em inglês) (ZENI, 2004, p. 4).

A opção por esse conteúdo de ensino emergiu em virtude do caráter multidimensional que o hip hop oportuniza a seus praticantes, favorecendo, assim, uma melhor compreensão sobre as diversas manifestações da linguagem, a partir das internalizações e produções dos indivíduos, quanto como ferramenta de contestação à forma preconceituosa com que esses sujeitos são percebidos socialmente. Assim, a multidimensionalidade da linguagem presente na cultura hip hop pode ser, em suas variações, apropriada pelos sujeitos e incorporada às suas individualidades, 
transformando os conhecimentos culturalmente produzidos pela humanidade em conhecimentos dos indivíduos (VYGOTSKY, 2007).

No que tange ao ensino propriamente dito desse conteúdo, sua inserção ocorreu de forma gradativa, no início das atividades no ano de 2017. Ao longo das intervenções, os jovens e adultos com deficiência intelectual e autismo puderam acessar aos elementos culturais pertencentes ao movimento hip hop, com especial destaque para as práticas corporais urbanas da juventude que compõem essa cultura (break, o grafite, o rap, o DJ, o basquete de rua e o skate).

Dessa forma, o hip hop nos permitiu não somente tornar acessível um bem cultural, considerando suas diversas significações, mas também estimular a criatividade e valorização de suas produções, a partir das diferentes possibilidades linguísticas que essa cultura fomenta (gráfica, corporal, rítmica, visual, auditiva, oral). Nesse sentido, os distintos elementos do hip hop nos permitem compreender e analisar as diversas manifestações de linguagem produzidas.

Nesse movimento, o rap (rhythm and poetry, ritmo e poesia), ritmo de música que envolve, prioritariamente, as rimas e as poesias, possibilitou uma riqueza de apropriações e produções de linguagem, considerando as distintas formas de expressão dos alunos. Isso se evidenciava quando, ao som da base de rap, os alunos produziam rimas à sua maneira, por meio de sons emitidos com a boca, palavras que para eles eram significativas, ou gestos que realizavam ao segurar o microfone e balançar o corpo no ritmo.

Essa experiência permitiu, então, que os sujeitos se expressassem, criassem e compartilhassem suas mensagens por meio da música. Vale salientar que a ampliação das possibilidades de realização do rap, para além da manifestação oral socialmente instituída da linguagem, favoreceu a inclusão e a participação ativa de todos nas atividades.

Para além da mediação pedagógica, os materiais utilizados também facilitaram o processo de internalização. O microfone, por exemplo, mais que ampliar o som emitido, serviu como instrumento de mediação para apropriação do rap, por compor o visual de um MC. Já as batidas da música se mostraram signos representativos para a criação de sequências e formas de utilização dos sons que esse aluno era capaz de produzir. Assim, o processo de mediação, dado por meio de instrumentos e signos, mostrou-se essencial para o estímulo das atividades psicológicas voluntárias, intencionais, controladas pelos próprios alunos na internalização e produção (VYGOTSKY, 2007) do rap, bem como nas expressões corporais representativas da cultura hip hop. Por meio da internalização, portanto, as ações Ihes permitiam se apropriar do rap, possibilitando-lhes, posteriormente, transformá-lo.

No momento em que podiam representar um dos personagens que compunham a cultura hip hop (como o MC/rapper, por exemplo), os alunos podiam se reconhecer em papeis sociais dentro desse movimento, mostrando-se protagonistas em potencial de seu processo de ensino-aprendizagem (SÁ; SIQUARA; CHICON, 2015), o que é louvável, ao se considerar a ausência desses sujeitos em papeis de reconhecimento social. Mais que consumir cultura, podiam produzir cultura dignas de valor social. Eles 
Sugeriam palavras ou sons representativos para a composição de seus raps. A priori, pareciam temas desconexos, aleatórios, no entanto, a partir do que sugeriam, foi possível perceber como os elementos da cultura hip hop foram assimilados, como o aparecimento das palavras top rock (passo de break) e da palavra hip hop. Além disso, mesmo os que possuem uma oralidade diferente da utilizada pela maioria da população sem deficiência criaram sons, a partir de suas linguagens, como o Lucas sonorizando 'wolwolwol' e o 'tchá' do Guilherme.5 A conexão de todas as sugestões resultou em um rap: 'wolwolwol, jogar bola/ wolwolwol, rockrol/ tchã, tchã, DJ/ wolwolwol, deus, wolwolwol/ hip hop, top rock'. Esse foi o resultado de uma produção coletiva de um rap diferente, com todas as personalidades. Mesmo que estivessem juntos na sala, cada um criou seu próprio som, sem, necessariamente, imitar o colega. Contudo, essa ação não foi realizada de forma individualizada, considerando que, à medida que alguém criava, todos experimentavam essa produção até nascer o rap final. (DIÁRIO DE CAMPO, 19-10-2017).

Notamos, nesse episódio, a capacidade de criação dos alunos quando era valorizada a diversidade. Para observadores externos, a sequência criada não faria sentido, mas, para eles, foi demasiadamente significativa, pois sua forma de comunicação e produção cultural foi valorizada e incorporada às produções do grupo, que os reconheceu como parte de um coletivo ativo na cultura hip hop.

O beat box também contribuiu para a ampliação do repertório de linguagem dos alunos. Essa "[...] arte de imitar com a boca instrumentos musicais e outros sons consiste numa ocupação de destaque, deixando de figurar apenas como uma virtude do mestre de cerimônias para reivindicar o status de um elemento a mais dentro de toda a cultura hip hop" (ALVES, 2008, p. 46). Permitiu o acesso a um novo conhecimento e a ressignificação desse elemento, identificado principalmente pela percussão de boca e imitação vocal de sons diferentes, incorporando-o com o uso da percussão corporal e utilização de outros materiais.

Essa experiência oportunizou a criação dos alunos a partir de suas vivências, à medida que sons do cotidiano eram adicionados às suas produções. Reproduziam, então, sons de carros freando, portas batendo, buzinas, dentre outros do cotidiano, conforme suas significações pessoais, com a boca ou com outra percussão corporal (batidas no peito, estalar de dedos etc.).

Dessa forma, as internalizações de sons cotidianos e o que conheceram sobre beat box se somaram às suas novas criações, originando sons autênticos autorais, expressando, portanto, que "[...] o sujeito tem condição de acessar a cultura e (re)criar/(res)significar os seus conceitos, a partir dos significados que essa tem para si."”. Nessa direção, tanto o rap quanto o beat box contribuíram positivamente, conforme registramos em diário de campo:

$\mathrm{Na}$ dimensão do rap, criavam suas rimas, mas uma, em especial, foi internalizada por todos, a 'Eta, pau pereira', criada pelo aluno Gilberto.7 Essa produção merece destaque, considerando que Gilberto participa pouco de atividades coletivas e, com sua criação, foi possível incluí-lo ao grupo com mais facilidade. Gilberto pegou o microfone algumas vezes para cantar seu rap e isso motivou todo o grupo a cantar. O beat box foi

\footnotetext{
5 Aluno de 17 anos com diagnóstico de síndrome de Down e autismo. Emite alguns sons e palavras.

6 PINO, 2005, apud SÁ et al., 2015, p. 357.

7 Aluno de 35 anos com diagnóstico de síndrome de Asperger. Ele faz uso da linguagem oral socialmente instituída, mas se comunica de forma bem particular, devido à síndrome.
} 
explorado junto com o rap, assim, enquanto uns cantavam, outros podiam produzir o som de base com a boca ou, a partir dos materiais (latas e copos), dançavam break ao som das produções. Para acompanhar, usamos uma base eletrônica de hip hop de fácil assimilação, o que contribuiu com a marcação coletiva do ritmo. Acompanhar a base não significa apenas a reproduzir o som que estão ouvindo, não é uma reprodução impessoal, mas uma ressignificação. (DIÁRIO DE CAMPO, 19-10-2017).

O grafite foi outro elemento capaz de fomentar momentos de internalização e de criação dos alunos a partir de suas apropriações a respeito das aulas com o conteúdo proposto. Em suas produções, os jovens e adultos com deficiência, participantes da pesquisa, representavam, em traços feitos por sprays, tintas, lápis coloridos, giz, dentre outros tipos de materiais, aquilo que aprenderam e os elementos do hip hop. Eles ressignificavam as práticas das quais participavam em desenhos, melhor dizendo, em grafites. Essa ação possibilitou o registro de suas internalizações em outra forma de linguagem, a gráfica, ampliando ainda mais as possibilidades de uso da linguagem.

O fato de os alunos conseguirem resgatar na memória acontecimentos das aulas anteriores e relacioná-los com o conteúdo que estava sendo trabalhado indicanos a apropriação do que eles vinham vivenciando na aula. A representação disso, a partir de outra/nova forma de linguagem, no caso em grafite, evidencia a versatilidade linguística deles, reafirmando o caráter polifônico da linguagem. Assim, não podemos limitar a linguagem apenas à fala, especialmente quando pensamos em pessoas com deficiência intelectual e autismo, cuja linguagem oral, frequentemente, não se apresenta organizada. Esses sujeitos acabam por perder sua "voz", na medida em que as outras formas de expressão são negligenciadas, deixando-os à mercê da interpretação e da vontade de terceiros para se comunicar socialmente.

A proposta intencionou abrir leques de possibilidades de comunicação no que tange à internalização e à produção de linguagem para que, assim, as aulas fossem de fato inclusivas e cada um pudesse se constituir consumidor e produtor de cultura dentro de suas capacidades, dando continuidade a seu desenvolvimento humano. Compreendemos, então, que, quando o sujeito internaliza e cria sua própria linguagem, ele se reconhece como sujeito e se torna independente, potencializando sua relação social com o outro (SÁ et al., 2015). Isso aconteceu a partir das apropriações que fizeram, cada um a seu modo, respeitando suas singularidades, haja vista a dimensão criativa que essa cultura oportuniza a seus praticantes. Esse movimento se constituiu fundamental na/para a ressignificação do protagonismo e superação do tratamento infantilizado que esses indivíduos recebem devido à sua deficiência, visto que se valorizam mais suas dificuldades em detrimento de suas potencialidades.

\section{HIP HOP E O RECONHECIMENTO JUVENIL DE JOVENS E ADULTOS COM DEFICIÊNCIA INTELECTUAL E AUTISMO}

A condição de juventude e/ou fase adulta de pessoas com deficiência intelectual e autismo, em geral, é uma etapa da vida social que é por vezes negada devido à infantilização desse público por tempo indeterminado, em razão da 
demasiada valorização de suas limitações em detrimento de suas capacidades, além da superproteção familiar (SAWAIA, 2001).

Ainda de acordo com o autor (2001), a importância de estar em um contexto jovem e se sentir parte dessa categoria está no fato de ser um período em que é possível gozar da liberdade, mesmo que ainda não possa desprender-se totalmente de uma dependência familiar, passando a enxergar-se muito para além da infância. Nesse sentido, buscamos transformar o imaginário social a respeito da deficiência na juventude, considerando que os jovens se encontram marginalizados socialmente e vistos como crianças pela família por um longo período, o que gera efeitos sobre seu protagonismo social, privando-os do direito de viver plenamente essa fase da vida, atribuindo-lhes estigmas de limites e incapacidades.

Em contrapartida a essas representações, percebemos o quanto os princípios da cultura hip hop contribuem positivamente para a busca da autonomia e protagonismo dos alunos envolvidos neste estudo, por meio da vivência de seus elementos e das práticas corporais que o circundam. Essa situação pode ser notada no relato sobre o aluno Amós, ${ }^{8}$ apresentado a seguir, quando, ao ser convidado a participar da atividade que estava sendo proposta na aula, optou por fazer o que chamou mais sua atenção e que, aparentemente, tinha maior relação com sua personalidade, exercendo seu protagonismo social para fazer as próprias escolhas:

\begin{abstract}
$\mathrm{Na}$ aula, trabalhávamos com a turma o beat box, fomentando novas possibilidades de produção de sons pelo uso dos copos. No entanto, dispusemos, no canto da sala, uma picape de papelão artesanal que seria utilizada em momento posterior. Contudo, o aluno Amós, ao perceber a presença desse objeto, mostrou interesse em detrimento do que estava sendo proposto para o grupo na aula. Dessa forma, exerceu sua autonomia, ao escolher fazer algo diferente do que estava sendo realizado pelos demais. Entre participar da atividade com os copos e explorar aquele objeto, ele optou por manusear a picape de som, sem nenhum direcionamento. Amós se aproximou do material e começou a explorá-lo, colocando os fones de ouvido e manuseando o disco como se mixasse uma música, como fazem os DJs nas festas. Uma professora tentou convencê-lo a realizar a atividade que estava sendo proposta no momento, mas o aluno se recusou, colocou o fone e mostrou que era ali que ele queria ficar. Ele demonstrou que aquele simples objeto de papelão era mais significativo do que parecia ser, usando sua imaginação para, possivelmente, sentir-se líder do grupo enquanto ditava o ritmo das batidas dos copos com suas mixagens. (DIÁRIO DE CAMPO, 9-11-2017).
\end{abstract}

Vale salientar que a picape da situação narrada era adaptada, uma simulação confeccionada em papelão, com um único disco e som reproduzido por um celular oculto dentro da caixa, que podia ser manipulado por um aplicativo de mixagens, mas isso foi suficiente para que Amós se imaginasse um DJ, ressignificando o material e exercendo a função de escolher as músicas que seriam tocadas, mixandoas e gesticulando, como quem se comunicava com o público. As possibilidades que Amós teve para agir com liberdade surgiram de sua consciência e estão intimamente relacionadas com a sua imaginação. Nessa concepção, criatividade e autonomia andam de mãos dadas, considerando que alguns pressupostos para o desenvolvimento de ambas se assemelham. Dessa forma, a experiência do mundo,

8 Aluno de 18 anos com diagnóstico de síndrome de Down que vocaliza sons bem particulares. 
a interação e a construção ativa do conhecimento proporcionaram um impulso de criar e questionar (como fez Amós ao fazer valer sua vontade de ser DJ), além de desenvolver o sentido de cooperação e de diálogo (VIGOTSKI, 2007).

O DJ, ou disc jóquei, função da qual Amós se apropriou nas aulas, tinha a missão de se comunicar com o público presente, por meio dos sons e de discursos proferidos. Esse aluno utilizou, portanto, um elemento pouco trabalhado nas aulas, atendendo a seu interesse dentro do hip hop. Essa se tornou sua forma de comunicarse com os demais, o que foi muito positivo, considerando que ele não faz uso da linguagem oral sistematizada.

Sabendo disso, o relato supracitado nos mostra como esses sujeitos podem sim ser autônomos e escolher se aproximar mais ou menos de determinada atividade, de acordo com suas potencialidades, como Amós fez assumindo o papel de DJ. Esse aluno revelou que possui interesses próprios e que pessoas com deficiência intelectual não precisam de alguém falando ou escolhendo por elas o tempo todo, como acontece na maioria das vezes em casos de pessoas com esse tipo de deficiência, quando são exaltadas suas limitações, ao invés de se enaltecer aquilo que são capazes de fazer. Amós participou em outros momentos das demais atividades referentes ao hip hop, mas se sentiu tão atraído pela função de DJ, que mostrava não querer ser incomodado. Suas expressões indicavam satisfação com o que fazia. Nesse sentido, ao desenvolvermos as aulas, diante da independência dos alunos, deixamos de pedir ou dar a ordem de que fizessem a atividade principal proposta e passamos a dispor-Ihes outros materiais e oportunidades de realizar as atividades pelas quais se interessassem.

Desse modo, podemos notar como o hip hop potencializou as formas de compreensão e manifestação da linguagem desses sujeitos, os quais nem sempre têm espaço ou "voz", apontando-nos a importância de reconhecê-los como jovens e adultos que expõem suas escolhas e atitudes. Os jovens têm, no geral, a característica de criar meios para serem ouvidos, conceber uma cultura própria para se sentirem únicos e, ao mesmo tempo, pertencentes a uma sociedade (RECKZIEGEL; STIGGER, 2005).

Assim, foi durante as experiências com esse elemento, nas aulas, que vimos nossos alunos criar os passos de dança com autonomia. Passos esses que foram utilizados na construção de uma coreografia de break, reunindo as contribuições criativas de cada sujeito, fazendo com que as particularidades constituíssem uma produção coletiva. A valorização de suas criações no grupo permitia o reconhecimento de suas potencialidades e atitudes de liderança presentes na juventude, não só ao consumirem cultura, mas também quando trabalhavam ativamente em sua produção, contribuindo com a construção da identidade do grupo. Esses, assim como outros momentos já mencionados, afastavam os jovens de ações que os infantilizavam, atribuindo-lhes papéis ativos dentro do movimento hip hop, como jovens e adultos sem deficiência já costumam fazer cotidianamente, apresentando suas capacidades de criar e buscando a autonomia corporal e social (DAYRELL, 2003). 


\section{O HIP HOP E AS RELAÇÕES SOCIAIS/CULTURAIS: CAMINHOS PARA A INCLUSÃO}

O trato didático-pedagógico dado ao conteúdo hip hop se desdobrou positivamente, no que tange aos caminhos para a inclusão de jovens e adultos com deficiência intelectual e autismo, afinal o hip hop se mostrou um movimento cultural polifônico, capaz de agir como ferramenta de reconhecimento não só juvenil, mas também de resistência de minorias identitárias, que caracteriza também o público foco deste estudo.

A escolha desse conteúdo de ensino nos deu um leque de elementos que permitiram dar visibilidade às produções culturais de nossos alunos. Essas ações potencializam a importância do reconhecimento desses sujeitos como cidadãos que têm o direito e condições de ocupar todos os espaços sociais, buscando, assim, a superação do imaginário social de que eles devem ocupar as margens sociais e manter relações sociais somente com a família e usuários de instituições filantrópicas. É entendendo a importância das relações sociais para o desenvolvimento humano de qualquer sujeito, que afirmamos que eles também precisam criar novas relações sociais e culturais para se desenvolverem humanamente (GOÉS, 2000).

Nessa direção, a cultura hip hop se mostrou promovedora de momentos em que esses jovens conseguiram se ver inseridos, de fato, na sociedade por meio das relações sociais e culturais internalizadas e produzidas. Essa afirmação se valida em alguns relatos contidos no diário de campo, como no dia em que os alunos puderam participar de um evento social em um parque municipal. Além de nossos alunos e seus familiares, nesse evento, havia pessoas de todas as gerações. Em um palco, bandas tocavam e uma apresentadora anunciava as atrações, interagindo com o público. Quando um grupo de hip hop subiu no palco, imediatamente os jovens e adultos com deficiência, sujeitos desta pesquisa, dirigiram-se à frente para mostrar o que sabiam, por iniciativa própria, incentivando a participação das outras pessoas presentes na roda de break que eles próprios promoveram em paralelo à apresentação do grupo de hip hop. Nessa roda, cada um podia ir ao centro mostrar um pouco do que sabia. Assim, quando "[...] a disputa parece democrática, trata-se de um espaço delimitado por uma roda de onde um espectador se desprende e vira dançarino ao adentrá-la." (CORREIA; SILVA; FERREIRA, 2017, p. 214).

Esse momento evidenciou o quanto o protagonismo social se constitui como elemento fundamental na/para os processos de inclusão desses alunos, levandoos a se sentirem integrantes ativos do meio em que estão inseridos. Isso pode ser notado no relato a seguir:

\footnotetext{
Quando a apresentadora anunciou que haveria um grupo de rappers para se apresentar, os alunos logo se levantaram e foram para a frente do palco para prestigiar o grupo. Era nítido que estavam ali porque queriam e estavam gostando muito do que estava sendo cantado. Nesse espaço e tempo, observamos os nossos alunos lado a lado de outras pessoas da comunidade executando os passos de break que aprenderam e criaram durante todo o semestre nas aulas. Algumas pessoas até imitavam seus passos, abriram uma meia-lua e cada um ia ao centro demostrar o que se sabia do break, criando novos passos e ensinando algumas crianças que estavam do seu lado. Os nossos alunos animaram o final desse evento,
} 
pois foi pelas iniciativa deles de se dirigir à frente do palco que algumas pessoas se sentiram motivadas a dançar e cantar também. Alyne ${ }^{9}$ chegou a convidar algumas pessoas para dançar. (DIÁRIO DE CAMPO, 3-12-2017).

Acreditamos que, por meio de ações como a supracitada, os sujeitos mostraram-se cidadãos sociais ativos, à medida que têm a oportunidade de apresentar publicamente suas apropriações e produções culturais. Isso porque, mais que somente mostrar o que são capazes de fazer com a cultura hip hop, conseguem também agir como protagonistas do processo de alteração positiva do imaginário social a respeito da deficiência na fase adulta. Essa ação se constitui na construção e compartilhamento de novos saberes sobre a deficiência e participação na cultura, isso porque a construção do conhecimento ocorre a partir de processo intenso de interação social, e da inserção na cultura em sua diversidade, pois assim o sujeito se desenvolve humanamente e consegue contribuir para o desenvolvimento de outros (EMILIANO; TOMÁS, 2015, p. 60).

Além da ocupação de espaços sociais públicos e interação com os demais sujeitos da sociedade não pertencentes à família e das instituições educativas e filantrópicas das quais esses sujeitos participam, as práticas corporais produzidas pelo hip hop contribuíram para a interação entre os próprios alunos. Anteriormente, esses alunos tinham dificuldades de se relacionarem uns com os outros, estabelecendo relações sociais apenas com os professores e bolsistas, mantendo somente esses educadores como figura de referência. No decorrer do processo, a partir dessa construção coletiva e processual, o grupo passou a se constituir como uma equipe colaborativa e mais autônoma, demonstrando avanços na relação com os pares, passando a identificá-los como figuras de referência também, na medida em que ensinavam e aprendiam uns com os outros. Assim, as variadas formas de linguagens permitem ao homem estruturar seu pensamento, traduzir o que sente, registrar o que conhece e comunicar-se com outros homens, marcando, desse modo, seu ingresso na cultura (SÁ et al., 2015).

\section{CONSIDERAÇÕES FINAIS}

Em síntese, o hip hop serviu como instrumento de mediação potente aos processos inclusivos dos jovens e adultos com deficiência intelectual e autismo participantes deste estudo, pois proporcionou momentos de reconhecimento social, bem como de protagonismo e valorização de sua juventude.

A cada aula se notava como os elementos do hip hop em sua diversidade, atendiam às particularidades dos alunos, ampliando as formas de linguagem e promovendo a inclusão, ao oferecer meios distintos de participação. Além disso, ao considerar que o desenvolvimento humano se dá a partir do acesso à cultura, por meio das relações sociais, fica evidente como esse movimento permitiu que esses sujeitos potencializassem seu desenvolvimento a partir da apropriação de novos bens culturais, ampliando, assim, suas experiências a respeito do que já foi produzido pela sociedade.

9 Aluna de 29 anos com diagnóstico de deficiência intelectual. Ela faz uso da linguagem oral socialmente instituída. 
Vale salientar também que as diversas manifestações de linguagem produzidas - gráfica, corporal, visual, musical - pelos alunos revelaram suas capacidades criativas e o reconhecimento de que essas formas distintas de comunicação contribuiram com a distância na interlocução com demais sujeitos da sociedade. Por fim, o desdobramento desse conteúdo oportunizou a ocupação de espaços públicos, momentos em que a comunidade local pôde ter acesso à expressão cultural que esses jovens e adultos foram capazes de produzir por meio da transposição didática do hip hop.

\section{REFERÊNCIAS}

ALVES, Valmir Alcântara. De repente o rap na educação do negro: o rap do movimento hip hop nordestino como prática educativa da juventude negra. 2008. 135 f. Dissertação (Mestrado em Educação) - Universidade Federal da Paraíba, João Pessoa, 2008.

BAKHTIN, Mikhail. Marxismo e filosofia da linguagem. São Paulo: Hucitec, 1999.

BARBIER, René. A pesquisa-ação. Brasília, DF: Plano, 2002.

BARDIN, Laurence. Análise de conteúdo. Lisboa: Edições 70, 1977.

BARROS, Carolina Leite; TRUGILHO, Silvia Moreira. Direitos da pessoa com deficiência, transtorno do espectro autista e políticas públicas. In: MACHADO, Suzana Grimald.; LORETE, Eliane Oliveira (org.). Educação inclusiva: múltiplas práticas e olhares. Venda Nova do Imigrante, ES: Instituto Federal de Educação, Ciência e Tecnologia do Espírito Santo, 2019. p. 74-94.

CORREIA, Adriana Martins; SILVA, Carlos Alberto Figueiredo da; FERREIRA, Nilda. Teves. Do racha na rua à batalha no palco: cenas das danças urbanas. Motrivivência, v. 29, n. 50, p. 213-231, abr. 2017. Disponível em: https://periodicos.ufsc.br/index.php/motrivivencia/ article/view/2175-8042.2017v29n50p213. Acesso em: 20 out. 2018.

DAYRELL, Juarez. O jovem como sujeito social. Revista Brasileira de Educação, n. 24, p. 40-52, set./dez. 2003.

EMILIANO, Joyce Monteiro; TOMÁS, Débora Nogueira. Vigotsky: a relação entre afetividade, desenvolvimento e aprendizagem e suas implicações na prática docente. Cadernos de Educação: Ensino e Sociedade, v. 2, n.1, p. 59-72, 2015.

GOES, Maria Cecília Rafael de. A formação do indivíduo nas relações sociais: contribuições teóricas de Lev Vigotski e Pierre Janet. Educação e Sociedade [on-line], v. 21, n. 71, p. 116-131, 2000.

LIMA, Patrícia Oliveira de Daniele; SILVA, Ana Marcia. Para além do hip hop: juventude, cidadania e movimento social. Motrivivência, ano XVI, n. 23, p. 61-80, 2004.

RECKZIEGEL, Ana Cecilia de Carvalho; STIGGER, Marco Paulo. Dança de rua: opção pela dignidade e compromisso social. Movimento, v. 11, n. 2, p. 59-73, 2005.

SA, Maria das Graças Carvalho Silva de; SIQUARA, Zelinda Orlandi; CHICON, José Francisco. Representação simbólica e linguagem de uma criança com autismo no ato de brincar. Revista Brasileira de Ciências do Esporte, v. 37, n. 4, p. 355-361, 2015. 
SALTON, Bruna Polleto; AGNOL, Anderson Dall; TURCATTI, Alissa. Manual de acessiblidade em documentos digitais. Bento Gonçalves, RS: Instituto Federal de Educação, Ciência e Tecnologia do Rio Grande do Sul, 2017.

SAWAIA, Bader. O sofrimento ético-político como categoria de análise da dialética da exclusão/inclusão. In: SAWAIA, Bader. (org.). As artimanhas da exclusão: análise psicossocial e ética da desigualdade social. 2. ed. Petrópolis: Vozes, 2001. cap. 6, p. $97-$ 118.

VYGOTSKY Lev. Semyonovich. A formação social da mente. 7. ed. São Paulo: Martins Fontes, 2007.

ZENI, Bruno. O negro drama do rap: entre a lei do cão e a lei da selva. Rio de Janeiro: Estudos Avançados, 2004. 